\title{
A case of acquired right-sided subclavian steal syndrome successfully treated with stenting using brachial approach
}

\author{
Dragan Dragičević ${ }^{1^{*}}$, Maja Škorić ${ }^{2}, K_{\text {rešimir Kolić }}{ }^{1}$, Marina Titlić ${ }^{3}$ \\ ${ }^{1}$ Department of Diagnostic and Interventional Radiology, University Hospital Center Split, Split, Croatia; \\ *Corresponding Author: dragandragicevic1@gmail.com \\ ${ }^{2}$ Department of Radiology, General Hospital “Hrvatski Ponos” Knin, Knin, Croatia \\ ${ }^{3}$ Department of Neurology, University Hospital Center Split, Split, Croatia
}

Received 5 December 2013; revised 2 January 2014; accepted 1 February 2014

Copyright (C) 2014 Dragan Dragičević et al. This is an open access article distributed under the Creative Commons Attribution License, which permits unrestricted use, distribution, and reproduction in any medium, provided the original work is properly cited. In accordance of the Creative Commons Attribution License all Copyrights (C) 2014 are reserved for SCIRP and the owner of the intellectual property Dragan Dragičević et al. All Copyright @ 2014 are guarded by law and by SCIRP as a guardian.

\section{ABSTRACT}

Subclavian steal syndrome (SSS) is defined as a group of symptoms that arise from reversed blood flow in the ipsilateral vertebral artery. It is the consequence of proximal occlusion or highgrade stenosis of the subclavian artery. The subclavian obstructive lesions are mostly located in the proximal segment of the subclavian artery and predominantly on the left side. In contrast, there are only a small number of patients that present with right-sided symptoms and even fewer with bilateral symptoms. Endovascular therapy of occlusions and high-grade stenosis of subclavian artery proximal to the origin of the vertebral artery becomes an established therapy in last two decades. We report a case of successful endovascular treatment of right-sided subclavian steal and high-grade (80\%) right subclavian artery stenosis due to atherosclerotic occlusive disease with balloon-expandable stent using brachial approach.

\section{KEYWORDS}

\section{Subclavian Steal Syndrome; Right-Sided;} Stenting; Brachial Approach

\section{INTRODUCTION}

Subclavian steal syndrome (SSS) is defined as a group of symptoms that arise from reversed blood flow in the ipsilateral vertebral artery although the term syndrome is usually attributed to clinical symptomatic presentation
[1]. Patients with subclavian steal are usually asymptomatic, though they may present with transient ipsilateral arm claudication, symptoms of posterior cerebral circulation, and/or cardiac ischemia in patients undergoing coronary artery bypass graft (CABG) surgery with left internal mammary artery (LIMA) as the graft $[2,3]$.

The non-invasive color Doppler ultrasonography (CDUS) is now regarded as the standard screening tool for the SSS. An arm blood pressure difference greater than $20 \mathrm{~mm} \mathrm{Hg}$ has been proven to be a sensitive threshold for the detection of the subclavian steal. CT or MR angiography is the confirmatory test for any suspected subclavian steal cases found on ultrasound examinations [4].

Traditionally, surgical revascularization has been the preferred treatment option with acceptable long-term results [5]. However, over the last two decades, endovascular therapy of localized supra-aortic vessel disease becomes an established therapy [6,7].

In this article, we report a case of successful endovascular treatment of acquired right-sided subclavian steal and high-grade $(80 \%)$ right subclavian artery stenosis due to atherosclerotic occlusive disease with balloonexpandable stent using brachial approach.

\section{THE CASE REPORT}

A 73-year-old white male patient with a 1-year history of vertigo and the other vertebrobasilar symptoms presented for evaluation. He had a past medical history of diabetes mellitus type II. Physical examination revealed significant systolic blood pressure difference between the arms of $15 \mathrm{~mm} \mathrm{Hg}$ (140 on the left side versus 125 on the right side). 
CDUS showed retrograde right vertebral artery flow with the parvus-tardus waveform in the ipsilateral subclavian artery which confirmed the diagnosis of rightsided SSS.

MSCT angiography of the supra-aortal branches was performed and revealed an eccentric calcified high-grade (80\%) stenosis in proximal segment of the right subclavian artery.

Our chose was the endovascular treatment of this lesion, so we started the procedure with standard digital subtraction (DSA) arch aortography under local anesthesia via a unilateral femoral approach using $5 \mathrm{~F}$ angulated pig-tail catheter followed by selective angiography of the brachiocephalic trunk using $5 \mathrm{~F}$ headhunter 1 catheter (Figure 1). We confirmed the diagnosis of an eccentric high-grade stenosis of the right subclavian artery close to its origin as well as the reversal of flow in the right vertebral artery. Despite several attempts we couldn't cross the lesion by the guide-wire so we decided to withdraw the femoral access and use the only right brachial approach. After successful puncture of the distal segment of the right brachial artery, $7 \mathrm{~F}$ sheet was introduced with its tip into the axillar artery (Figure 1).

Now we were able to cross the lesion by standard 0.038-inch Terrumo guide-wire (from the right axillar artery into the aorta) followed by $5 \mathrm{~F}$ straight angiographic catheter. First we performed the pre-dilatation using $8 \times 20 \mathrm{~mm}$ balloon (Figure 1) and then $10 \times 20$ $\mathrm{mm}$ balloon-expanding stent was placed. On the postinterventional angiography we can see successfully restituted patency of the right subclavian artery without residual stenosis (Figure 1).

24 hours after the intervention CDUS was performed. It revealed restored antegrade right vertebral artery flow as well as regular flows in the ipsilateral subclavian and brachial artery as confirm of the success of the endovascular intervention.

The patient had no adverse events.

\section{DISCUSSION}

Subclavian artery occlusive disease occurs in relatively younger patients (mean age 49 - 69 years) than more common types of atherosclerotic disease [8-10]. While in most reports there is only slight predominance of male patients, female patients have represented the majority in several studies [11,12]. The most common cause of subclavian artery occlusive disease is atherosclerosis, followed far less often by Takayasu's arteritis. Rarely, radiation-induced atherosclerosis obliterans is a cause [13].

The acquired subclavian steal syndrome is mostly leftsided with Labropoulos et al. reporting $82.3 \%$ of their cases [14]. Shillinger et al., Staikov et al. and de Vries et al. in their studies showed that the subclavian obstructive lesions are mostly located in the proximal segment of the subclavian artery, proximal to the origin of the vertebral artery and predominantly on the left side $[11,15,16]$. Because the left subclavian artery has a more prominent angle at its origin, it is likely that turbulent flow patterns in the aortic arch and at the origin of the subclavian artery are responsible for extensive plaque formation at this particular location accelerating atherosclerosis [17, 18].

In contrast, there are only a small number of patients that present with right-sided symptoms and even fewer with bilateral [19-21].

For either surgical or endovascular treatment, the indications are as follows: vertebrobasilar ischemia [22-25], upper limb ischemia, hand "claudication" and digital embolization [12,26,27], both of the preceding [24], angina in patients with a LIMA graft $[28,29]$ and leg claudication in patients with axillo-femoral grafts [29]. Additional indications include increased flow for schedule operative procedure (i.e., LIMA graft, axillofemoral graft, dialysis graft) [30].

Operative methods include carotid-subclavian and axillo-axillary bypass using synthetic grafts or saphenous vein, or transposition of the subclavian artery up to the common carotid artery [31,32]. Perioperative mortality is low $(0 \%-0.8 \%)$, and stroke rate ranges from $0.5 \%$ to $5 \%$. Five-year primary patency rates range from $92 \%$ to $95 \%$, and 8 - 10 year primary patency ranges from $83 \%$ to $95 \%$ [33-35].

The development of percutaneous methods for the treatment of SSS has revolutionized the management of these patients, mainly by decreasing the complication rate [36].

These methods mainly include PTA and stenting.

Several reports of PTA for proximal subclavian artery obstructive disease showed high rates of technical success with low complication rates $[25,37,38]$.

Erbstein et al. reported a rate of success of $88 \%$ in 24 patients treated with PTA of the proximal subclavian artery [39]. Bachman and Kim described a successful outcome using PTA for the treatment of SSS [40]. Motarjeme et al. in a review about PTA of the supra-aortic vessels, studied 112 patients that were submitted to treatment of 151 lesions in the innominate, subclavian, carotid, and vertebral arteries. PTA achieved a rate of success of $100 \%$ in subclavian artery stenosis $(n=67)$. In 13 cases of subclavian artery occlusion, however, only 6 (46\%) were recanalized. They concluded that PTA can achieve excellent immediate and long-term results in proximal subclavian artery stenosis, however subclavian artery occlusions may not respond well to PTA, and those successfully recanalized have a high reocclusion rate (50\%) [6].

Although the initial success rate of PTA is high, the long-term angiographic patency is unclear and not ac- 

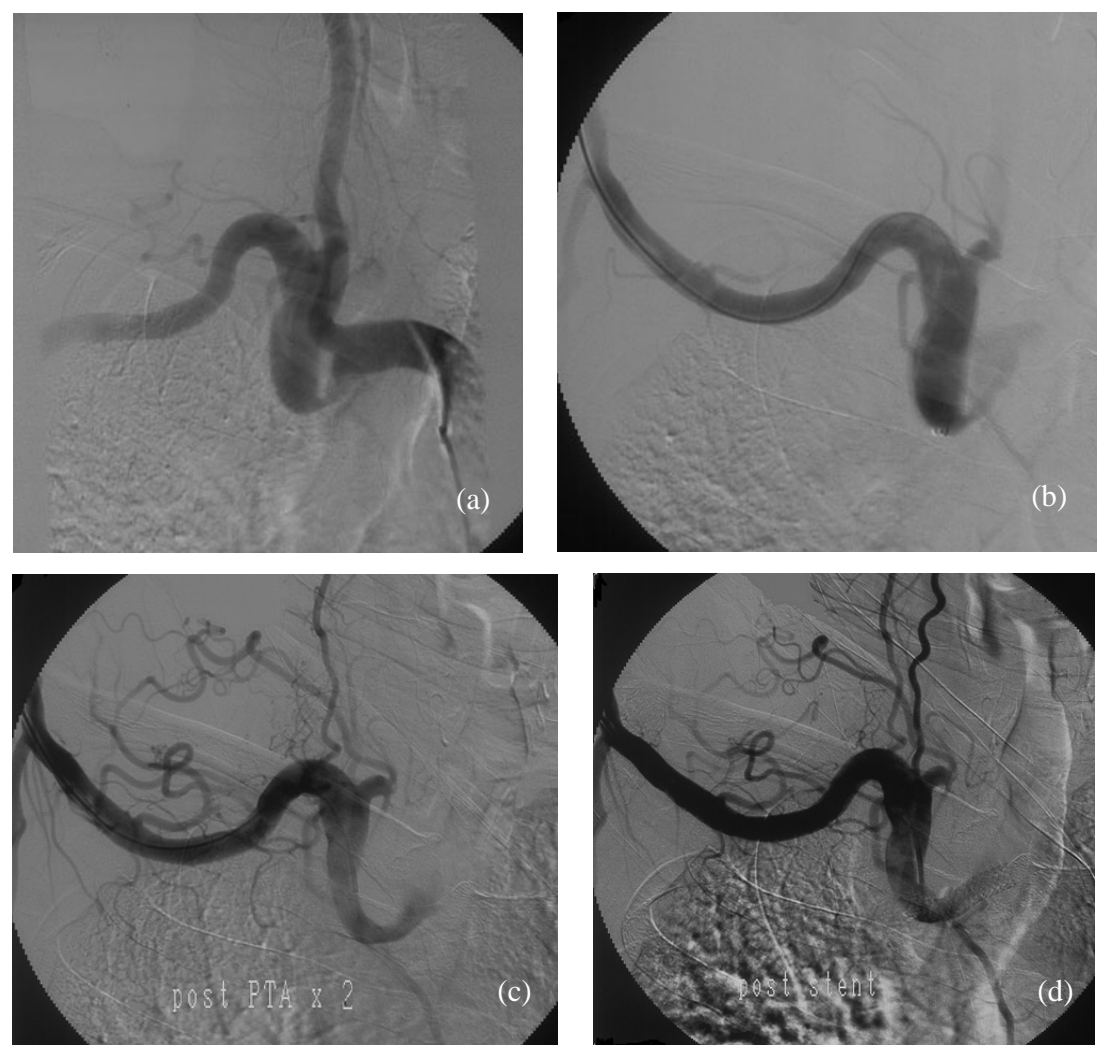

Figure 1. (a) Selective DSA of the brachiocephalic trunk showing eccentric high-grade stenosis of the right subclavian artery close to its origin; (b) Catheterization of the right subclavian artery via transbrachial approach; (c) Control angiography after balloon dilatation of the lesion showing minimal residual stenosis; (d) Successfully restituted patency of the right subclavian artery without residual stenosis after deployment of balloon-expandable stent.

ceptable in many reports [26,41].

The use of stents appears to improve both acute and long-term results [42]. Mathias et al. reported acceptable initial successful treatment rate of $83 \%$ and low rate of re-occlusion in $2 \%$ for subclavian artery occlusions with self-expanding stent [43]. In study of Sakai et al. results are even better with $89.3 \%$ successful rate of recanalization and no re-occlusion in the follow-up period, as balloon-expandable stent used in this series [44].

Stenting has been considered safe. Risks related to this procedure are stroke, arterial rupture and reocclusion [45-47]. Stenting may increase the initial success in recanalization of occlusions, improve long-term patency, and protect atheromatous debris or thrombus from dislodgement during PTA by trapping this material between the vessel wall and the stent mesh [48].

Sakai et al. treated 26 patients with 28 lesions (2 of patients had bilateral lesions) in their study. They reported successful endovascular treatment of 5 right-sided SSS due to atherosclerotic occlusive disease. Two of these patients had bilateral subclavian artery occlusions and other three cases were associated with high-grade internal carotid artery stenosis [44]. They didn't report any successfully treated isolated right subclavian artery lesions as it was in our case.

De Vries et al. were treated 110 patients with lesions of subclavian artery proximal to the origin of the vertebral artery. The left subclavian artery was involved in 84 cases, and 26 lesions were right-sided. Of the 8 failures, 1 referred on right subclavian artery occlusion and regarding complications, 2 patients with major or minor stroke had multiple-vessel extracranial disease in combination with right-sided subclavian artery obstruction. They suggested that PTA of the right subclavian artery is a riskier procedure, even without extensive extracranial artery disease, because of the proximity of the common carotid artery. It can be assumed that patients with this combination of disease are at higher risk for thromboembolic complications of the carotid and middle cerebral arteries. In their opinion, subclavian artery transposition in these patients might be a useful alternative. In their study, a femoral approach was used in 89 patients, brachial approach in 6 patients and in 15 procedures, a combined femoral and brachial approach was used [18]. They didn't report that any of these 26 right-sided lesions were treated using only brachial approach, and even, the 
number of treated isolated right-sided lesions (without multiple-vessel extracranial disease) was unknown.

Wang et al. reported the results of endovascular treatment of 59 patients with 46 left-sided subclavian artery lesions, 11 of lesions were right-sided and 2 patients had bilateral subclavian artery disease. They used femoral approach in 47 procedures, combined femoral and brachial approach in 11 procedures, and brachial approach in 2 procedures. One of two patients which were treated using brachial approach had bilateral subclavian disease and the other one had left-sided lesion. On the other hand, all stenting in this series were performed using self-expanding stents instead of balloon-expandable stents [48].

So, to the best of our knowledge, nobody described a case of successfully treated symptomatic acquired (atherosclerotic) right-sided high-grade subclavian artery stenosis with balloon-expandable stent using brachial approach. In our case the lesion was isolated - neither bilateral subclavian, nor connected with multiple-vessel extracranial disease. The procedure was facilitated with a main advantage of the brachial approach — shorter and less tortuous path to the lesion.

\section{CONCLUSION}

Although it is generally believed that endovascular recanalization (PTA or stenting) of the right subclavian artery is a riskier procedure, and especially of higher risk for thromboembolic complications, primary stenting of these lesions with high radial force balloon-expandable stents using brachial approach might be a safe and valid alternative to surgery.

\section{REFERENCES}

[1] Miller Fischer, C. (1961) A new vascular syndrome "The subclavian steal”. New England Journal of Medicine, 265, 912-913. http://dx.doi.org/10.1056/NEJM196111022651812

[2] Taylor, C.L., Selman, W.R. and Ratcheson, R.A. (2002) Steal affecting the central nervous system. Neurosurgery, 50, 679-688. http://dx.doi.org/10.1097/00006123-200204000-00002

[3] Hennerici, M., Klemm, C. and Rautenberg, W. (1988) The subclavian steal phenomenon: A common vascular disorder with rare neurologic deficits. Neurology, 38, 669673. http://dx.doi.org/10.1212/WNL.38.5.669

[4] Osiro, S., Zurada, A., Gielecki, J., Shoja, M.M., Tubbs, R.S. and Loukas, M. (2012) A review of subclavian steal syndrome with clinical correlation. Medical Science Monitor, 18, 57-63. http://dx.doi.org/10.12659/MSM.882721

[5] Edwards Jr., W.H., Tapper, S.S., Edwards Sr., W.H., Mulherin Jr., J.L., Martin 3rd, R.S. and Jenkins, J.M. (1994) Subclavian revascularization. A quarter century experience. Annals of Surgery, 219, 673-677. http://dx.doi.org/10.1097/00000658-199406000-00010

[6] Motarjeme, A. (1996) Percutaneous transluminal angioplasty of supra-aortic vessels. Journal of Endovascular Surgery, 3, 171-181.

http://dx.doi.org/10.1583/1074-6218(1996)003<0171:PT $\underline{\text { ASAV }>2.0 . \mathrm{CO} ; 2}$

[7] Motarjeme, A. and Gordon, G.I. (1993) Percutaneous transluminal angioplasty of the brachiocephalic vessels: Guidelines for therapy. International Angiology, 12, 260269.

[8] Carlson, R.E., Ehrenfeld, W.K., Stoney, R.J. and Wylie, E.J. (1977) Innominate artery endarterectomy. A 16-year experience. Archives of Surgery, 112, 1389-1393. http://dx.doi.org/10.1001/archsurg.1977.01370110123014

[9] Kieffer, E., Sabatier, J., Koskas, F. and Bahnini, A. (1995) Atherosclerotic innominate artery occlusive disease: Early and long-term results of surgical reconstructions. Journal of Vascular Surgery, 2, 326-336. http://dx.doi.org/10.1016/S0741-5214(95)70273-3

[10] Berguer, R., Monasch, M.D. and Kline, R.A. (1998) Transthoracic repair of innominate and common carotid artery disease: Immediate and long term outcome for 100 consecutive surgical reconstructions. Journal of Vascular Surgery, 27, 34-41. http://dx.doi.org/10.1016/S0741-5214(98)70289-7

[11] Schillinger, M., Haumer, M., Schillinger, S., Ahmadi, R. and Minar, E. (2001) Risk stratification for subclavian artery angioplasty: Is there an increased rate of restenosis after stent implantation? Journal of Endovascular Therapy, 8, 550-557.

http://dx.doi.org/10.1583/1545-1550(2001)008<0550:RS FSAA $>2.0 . \mathrm{CO} ; 2$

[12] Bates, M.C., Broce, M., Lavigne, P.S. and Stone, P. (2004) Subclavian artery stenting: Factors influencing long-term outcome. Catheterization and Cardiovascular Interventions, 61, 5-11. http://dx.doi.org/10.1002/ccd.10711

[13] Alcocer, F., David, M., Goodman, R., Jain, S.K. and David, S. (2013) A forgotten vascular disease with important clinical implications. Subclavian steal syndrome. American Journal of Case Reports, 14, 58-62. http://dx.doi.org/10.12659/AJCR.883808

[14] Labropoulos, N., Nandivada, P. and Bekelis, K. (2010) Prevalence and impact of the subclavian steal syndrome. Annals of Surgery, 252, 166-170. http://dx.doi.org/10.1097/SLA.0b013e3181e3375a

[15] Schillinger, M., Haumer, M., Schillinger, S., Mlekusch, W., Ahmadi, R. and Minar, E. (2002) Outcome of conservative versus interventional treatment of subclavian artery stenosis. Journal of Endovascular Therapy, 9, 139146.

http://dx.doi.org/10.1583/1545-1550(2002)009<0139:OO CVIT>2.0.CO;2

[16] Staikov, I.N., Do, D.D., Remonda, L., Mattle, H., Baumgartner, R. and Schroth, G. (1999) The site of atheromatosis in the subclavian and vertebral arteries and its implication for angioplasty. Neuroradiology, 41, 537-542. http://dx.doi.org/10.1007/s002340050800

[17] Nicholls, S.C., Koutlas, T.C. and Strandness, D.E. (1991) Clinical significance of retrograde flow in the vertebral 
artery. Annals of Vascular Surgery, 5, 331-336. http://dx.doi.org/10.1007/BF02015293

[18] De Vries, J.P., Jager, L.C., Van den Berg, J.C., Overtoom, T.T., Ackerstaff, R.G., Van de Pavoordt, E.D. and Moll, F.L. (2005) Durability of percutaneous transluminal angioplasty for obstructive lesions of proximal subclavian artery: Long-term results. Journal of Vascular Surgery, 41, 19-23. http://dx.doi.org/10.1016/j.jvs.2004.09.030

[19] Tan, T.Y., Schminke, U., Lien, L.M. and Tegeler, C.H. (2002) Subclavian steal syndrome: Can the blood pressure difference between arms predict the severity of steal? Journal of Neuroimaging, 12, 131-135. http://dx.doi.org/10.1111/j.1552-6569.2002.tb00109.x

[20] Bornstein, N.M. and Norris, J.W. (1986) Subclavian steal: A harmless hemodynamic phenomenon? Lancet, 2, 303305.

[21] Smith, J.M., Koury, H.I., Hafner, C.D. and Welling, R.E. (1994) Subclavian steal syndrome. A review of 59 consecutive cases. Journal of Cardiovascular Surgery (Torino), 35, 11-14. http://dx.doi.org/10.1016/S0140-6736(86)90002-4

[22] Guan, H., Liu, C.W. and Xiao, Y. (1994) Subclavian steal syndrome: A report of 25 cases. Chinese Medical Journal, 32, 154-156.

[23] Motarjeme, A., Keifer, J.W., Zuska, A.J. and Nabawi, P. (1985) Percutaneous transluminal angioplasty for treatment of subclavian steal. Radiology, 155, 611-613.

[24] Wilms, G., Baert, A., Dewaele, D., Vermylen, J., Nevelsteen, A. and Suy, R. (1987) Percutaneous transluminal angioplasty of the subclavian artery: Early and late results. Cardiovascular Interventional Radiology, 10, 123-128. http://dx.doi.org/10.1007/BF02577985

[25] Sullivan, T.M., Gray, B.H., Bacharach, J.M., Perl 2nd, J., Childs, M.B., Modzelewski, L. and Beven, E.G. (1998) Angioplasty and primary stenting of the subclavian, innominate, and common carotid arteries in 83 patients. Journal of Vascular Surgery, 28, 1059-1065. http://dx.doi.org/10.1016/S0741-5214(98)70032-1

[26] Henry, M., Amor, M., Henry, I., Ethevenot, G., Tzvetanov, K. and Chati, Z. (1999) Percutaneous transluminal angioplasty of the subclavian arteries. Journal of Endovascular Surgery, 6, 33-41. http://dx.doi.org/10.1583/1074-6218(1999)006<0033:PT AOTS $>2.0 . \mathrm{CO} ; 2$

[27] Westerband, A., Rodriguez, J.A., Ramaiah, V.G. and Diethrich, E.B. (2003) Endovascular therapy in prevention and management of coronary-subclavian steal. Journal of Vascular Surgery, 38, 699-703. http://dx.doi.org/10.1016/S0741-5214(03)00728-6

[28] Martinez, R., Rodriguez-Lopez, J., Torruella, L., Ray, L., Lopez-Galarza, L. and Diethrich, E.B. (1997) Stenting for occlusion of the subclavian arteries. Technical aspects and follow-up results. Texas Heart Institute Journal, 24, 23-27.

[29] Al-Mubarak, N., Liu, M.W., Dean, L.S., Al-Shaibi, K., Chastain 2nd, H.D., Lyer, S.S. and Roubin, G.S. (1999) Immediate and late outcomes of subclavian artery stenting. Catheterization and Cardiovascular Interventions, 46, 169-172.
http://dx.doi.org/10.1002/(SICI)1522-726X(199902)46:2 $<169::$ AID-CCD11>3.0.CO;2-4

[30] Rodriguez-Lopez, J.A., Werner, A., Martinez, R., Torruella, L.J., Ray, L.I. and Diethrich, E.B. (1999) Stenting for atherosclerotic occlusive disease of the subclavian artery. Annals of Vascular Surgery, 13, 254-260.

http://dx.doi.org/10.1007/s100169900254

[31] Diethrich, E.B., Garrett, H.E., Ameriso, J., Crawford, E.S., El-Bayar, M. and De Bakey, M.E. (1967) Occlusive disease of the common carotid and subclavian arteries treated by carotid-subclavian bypass. The American Journal of Surgery, 114, 800-808. http://dx.doi.org/10.1016/0002-9610(67)90151-1

[32] Parrott, J.C. (1964) The subclavian steal syndrome. JAMA, 88, 661-665. http://dx.doi.org/10.1001/archsurg.1964.01310220151023

[33] Vitti, M.J., Thompson, B.W., Read, R.C., Gagne, P.J., Barone, G.W., Barnes, R.W. and Eidt, J.F. (1994) Carotidsubclavian bypass: A twenty-two-year experience. Journal of Vascular Surgery, 20, 411-417. http://dx.doi.org/10.1016/0741-5214(94)90140-6

[34] Perler, B.A. and Williams, G.M. (1990) Carotid-subclavian bypass: A decade of experience. Journal of Vascular Surgery, 12, 716-722. http://dx.doi.org/10.1067/mva.1990.24577

[35] Kretschmer, G., Teleky, B., Marosi, L., Wagner, O., Wunderlich, M., Karnel, F., Jantsch, H., Schemper, M. and Polterauer, P. (1991) Obliterations of the proximal subclavian artery: To bypass or to anastomose? Journal of Cardiovascular Surgery (Torino), 32, 334-339.

[36] Palchik, E., Bakken, A.M., Wolford, H.Y., Saad, W.E. and Davies, M.G. (2008) Subclavian artery revascularization: An outcome analysis based on mode of therapy and presenting symptoms. Annals of Vascular Surgery, 22, 70-78. http://dx.doi.org/10.1016/j.avsg.2007.07.020

[37] Motarjeme, A., Keifer, J.W. and Zuska, A.J. (1982) Percutaneous transluminal angioplasty of the brachiocephalic arteries. American Journal of Roentgenology, 138, 457462. http://dx.doi.org/10.2214/ajr.138.3.457

[38] Kandarpa, K., Becker, G.J., Ferguson, R.D., Connors III, J.J., Wojak, J.C. and Landow, W.J. (2001) Transcatheter interventions for the treatment of peripheral atherosclerotic lesions: Part II. Journal of Vascular and Interventional Radiology, 12, 807-812. http://dx.doi.org/10.1016/S1051-0443(07)61504-8

[39] Erbstein, R.A, Wholey, M.H. and Smoot, S. (1988) Subclavian artery steal syndrome: Treatment by percutaneous transluminal angioplasty. American Journal of Roentgenology, 151, 291-294. http://dx.doi.org/10.2214/ajr.151.2.291

[40] Bachman, D.M. and Kim, R.M. (1980) Transluminal dilatation for subclavian steal syndrome. American Journal of Roentgenology, 135, 995-996. http://dx.doi.org/10.2214/ajr.135.5.995

[41] Hadjipetrou, P., Cox, S., Piemonte, T. and Eisenhauer, A. (1999) Percutaneous revascularization of atherosclerotic obstruction of aortic arch vessels. Journal of the American College of Cardiology, 33, 1238-1245. http://dx.doi.org/10.1016/S0735-1097(98)00690-1 
[42] Amor, M., Eid-Lidt, G., Chati, Z. and Wilentz, J.R. (2004) Endovascular treatment of the subclavian artery: Stent implantation with or without predilatation. Catheterization and Cardiovascular Interventions, 63, 364-370. http://dx.doi.org/10.1002/ccd.20173

[43] Mathias, K.D., Luth, I. and Haarmann, P. (1993) Percutaneous transluminal angioplasty of proximal subclavian artery occlusions. Cardiovascular and Interventional $\mathrm{Ra}$ diology, 16, 214-218. http://dx.doi.org/10.1007/BF02602963

[44] Sakai, C., Sakai, N., Kuroiwa, T., Ishihara, H., Adachi, H., Morizane, A., Yano, T., Kajikawa, R., Yamagami, H., Kobayashi, J., Kondo, K. and Kikuchi, H. (2007) Stenting for chronic total occlusion of the proximal subclavian artery. Interventional Neuroradiology, 13, 135-140.

[45] Kumar, K., Dorros, G., Bates, M.C., Palmer, L., Mathiak, L. and Dufek, C. (1995) Primary stent deployment in occlusive subclavian artery disease. Catheterization and Car- diovascular Diagnosis, 34, 281-285. http://dx.doi.org/10.1002/ccd.1810340202

[46] Sueoka, B.L. (1996) Percutaneous transluminal stent placement to treat subclavian steal syndrome. Journal of Vascular and Interventional Radiology, 7, 351-356. http://dx.doi.org/10.1016/S1051-0443(96)72865-8

[47] Sakaida, H., Sakai, N., Nagata, I., Sakai, H., Iihara, K., Higashi, T., Kogure, S., Takahashi, J., Ohta, H., Nagamine, T., Anei, R., Soeda, A., Taniguchi, A., Shindo, A. and Kikuchi, H. (2001) Stenting for the occlusive carotid and subclavian arteries in Takayasu arteritis. No Shinkei Geka, 29, 1033-1041.

[48] Wang, K.Q., Wang, Z.G., Yang, B.Z., Yuan, C., Zhang, W.D., Yuan, B., Xing, T., Song, S.H., Li, T., Liao, C.J. and Zhang, Y. (2010) Long-term results of endovascular therapy for proximal subclavian artery obstructive lesions. Chinese Medical Journal, 123, 45-50.

\section{ABBREVIATIONS}

CABG = coronary artery bypass graft

CDUS $=$ color Doppler ultrasound

CT = computed tomography

DSA = digital subtraction angiography

LIMA = left internal mammary artery

$\mathbf{M R}=$ magnetic resonance

MSCT = multi-slice computed tomography

PTA = percutaneous transluminal angiography

SSS $=$ subclavian steal syndrome 